\title{
Viscum album L. \& Abies alba borisii regis effects on platelet aggregation and tumor metastasis
}

Ioannis Zelovitis ${ }^{1}$, Dimitrios Peschos ${ }^{1}$, Vasilios Ragos ${ }^{2}$, Anna-Maria Vlachou ${ }^{3}$, Evangelos Kontargiris ${ }^{4}$, Irida Dhima ${ }^{1}$, Apostolos Scaltsoyiannes ${ }^{5}$, Yannis V. Simos ${ }^{1 *}$, Maria Chatzidimitriou ${ }^{6}$, Christianna Zachariou ${ }^{1}$, Panagiotis Grivas ${ }^{1}$, Angelos Evangelou ${ }^{1}$, Spyridon Karkabounas ${ }^{1}$

${ }^{1}$ Laboratory of Physiology, Medical Department, University of Ioannina, 45110 Ioannina, Greece.

${ }^{2}$ Clinic of Maxillofacial Surgery, Medical Department, University of Ioannina, 45110 Ioannina, Greece.

${ }^{3}$ Hellenic Agricultural Organization - Demeter/Dairy Research Department, 45221 Ioannina, Greece.

${ }^{4}$ Department of Nursing, Epirus Institute of Technology (T.E.I. of Epirus), 47100 Ioannina, Greece.

${ }^{5}$ Laboratory of Forest Genetics and Plant Breeding, Department of Forestry and Natural Environment, Aristotle University of Thessaloniki, 54124 Thessaloniki, Greece.

${ }^{6}$ Medical Laboratory Studies, Alexander Technological Educational Institute, 57400 Sindos, Greece.

\begin{tabular}{l}
\hline ARTICLE INFO \\
\hline Received on: $15 / 05 / 2018$ \\
Accepted on: $23 / 09 / 2019$ \\
Available online: 03/12/2019
\end{tabular}

\section{Key words:}

Viscum album L., Abies

alba, platelet aggregation,

metastasis, cancer.

\begin{abstract}
Viscum album L. is a widely used medicinal plant in cancer treatment, known since ancient times. The aim of this study was to investigate the antimetastatic properties of the ethanolic extracts of synergistic plants $V$. album L. (epiphyte) and Abies alba (host) used alone or in combination (mixture). Inhibition of platelet aggregation was evaluated in washed rabbit and human platelets. Levels of thromboxane A2 $\left(\mathrm{TXA}_{2}\right)$ were estimated by radioimmune assay and natural killer cells (NKCs) cytotoxicity by flow cytometry. The antimetastatic properties of $V$. album L. and A. alba were studied in a tumor-bearing Wistar rat model. All extracts inhibited platelet aggregation in a dose-dependent manner as well as $\mathrm{TXA}_{2}$ production by three pathways of aggregation (adenosine diphosphate, platelet-activating factor, and arachidonic acid) while the mixture significantly increased NKCs cytotoxicity against cancer cells. In tumor-bearing Wistar rats, the treatment with the mixture of $V$. album L. and A. alba extract reduced the metastatic locations almost by $77 \%$. These data suggest that $V$. album L. and $A$. alba extract reduced metastasis through inhibition of platelet aggregation and amplification of the body defense mechanisms against cancer cells.
\end{abstract}

\section{INTRODUCTION}

Most cancer deaths are caused by metastasis rather than by the primary tumor (Yilmaz et al., 2007). Platelets have a role in cancer progression and metastasis that has largely been attributed to the platelet-mediated enhancement of tumor cell survival, extravasation, and angiogenesis (Gupta and Massague, 2004). Platelets form aggregates with tumor cells in circulation, facilitating their adhesion to leukocytes and to the vascular

\footnotetext{
"Corresponding Author

Yannis V Simos, Laboratory of Physiology, Medical Department, University of Ioannina, 45110 Ioannina, Greece.

E-mail:simosyannis@gmail.com
}

endothelium, promoting the metastatic cascade (Amo et al., 2014). Moreover, platelet aggregation around tumor cells inhibits in vitro NKCs tumorolytic activity and reduces the cytotoxic activity of tumor necrosis factor $\alpha$ (TNF- $\alpha$ ) (Gay and Felding-Habermann, 2011; Nieswandt et al., 1999). Once the tumor cells exit the circulation, factors derived from activated platelets promote neoangiogenesis, thereby enabling cancerous tumor growth at the metastatic site (Gay and Felding-Habermann, 2011; Nieswandt et al., 1999).

Viscum album L. belongs to the family Loranthaceae, commonly known as European mistletoe and it is native to Europe and Western and Southern Asia (Vidal-Russell and Daniel, 2008). Viscum album $L$. does not have the capacity for autonomous growth. In order to survive and reproduce, it uses by necessity a variety of hosts with which it establishes a synergistic, rather 
than a destructive parasitic relationship (as it is generally the case with other parasitic organisms of the plant kingdom). Common hosts of V. Album L. are Pinus halepensis, Abies alba, Quercus silicuastrum, Malus communis, and Flamuria melia (Böhling et al., 2003).

Viscum album L. extracts are often used in complementary and alternative medicine therapies for cancer (Horneber et al., 2008; Kienle et al., 2009; Steele et al., 2015). The anticancer properties of $V$. album $L$. have been attributed to various biologically active compounds. Among them, $V$. album L. lectins and triterpene acids have been extensively studied in different cancer models and were found to exert predominant cytotoxic activity (Choi et al., 2004; Delebinski et al., 2015; Twardziok et al., 2016). As for the cell death mechanisms triggered, the induction of apoptosis against different cancer cell lines was recorded (Choi et al., 2004; Delebinski et al., 2015; Kim et al., 2003; Lyu et al., 2002; Twardziok et al., 2016; Ucar et al., 2012).

The objective of this study was to investigate the antimetastatic properties of ethanolic extracts of synergetic plants $V$. album $L$. and its host $A$. alba in a series of in vitro, ex vivo, and in vivo experiments.

\section{MATERIALS AND METHODS}

\section{Preparation of $V$. album $L$. and $A$. alba extracts}

The $V$. album $L$. and A. alba (Abies borisii regis) plants were spotted in various areas of mountain Pindos in the Epirus Region, Greece. The soil where the plants developed was characterized as limestone. The host plant was Abies borisii regis which was a hybrid of $A$. alba $\times$ Abies cephalonica and the harvesting of $V$. album $L$. took place between late November and late February covering a period of about 100 days during the winter season. Identification of the plants was performed by Emeritus Professor P. Efthimiadis, Agricultural University of Athens. A voucher specimen for all the plants has been submitted to the Laboratory of Physiology, Faculty of Medicine, University of Ioannina (IZ-2014 $380^{\alpha}$ ) as a prerequisite of the doctoral dissertation of the main author of this article.

Three types of extracts were prepared: i) $V$. album $L$. (leaves and stems), ii) $A$. alba (leaves and barks), and iii) $1: 1 \mathrm{v} / \mathrm{v}$ mixture of $V$. album L. (leaves and stems) and A. alba (leaves and barks). Processing of the plant tissues took place entirely in a cold chamber at $4^{\circ} \mathrm{C}-8^{\circ} \mathrm{C}$. Leaves, barks, and small green stems were washed thoroughly with tap and deionized water and the moisture was removed by filter paper. All tissues were homogenized in ethanol using an electric blender. The pulverized plants were previously weighed so that each extract contained $30 \mathrm{~g}$ plant per $100 \mathrm{ml}$ of pure ethyl alcohol.

The extracts were placed in dark-brown amber flasks, while the air chamber of the bottles was filled with argon, sealed and placed in a cold chamber where they were stirred 1 hour per day with gentle circular agitation (40 rev/minutes for 60 minutes). After 30 days, the flasks were unsealed, the extract was filtered thoroughly through Whatman Grade 40 filters, and placed in airtight cryovials at $-80^{\circ} \mathrm{C}$, under an argon inert atmosphere. After 30 days, the extracts were dried in a stream of nitrogen under aseptic conditions and inserted into a lyophilizer vacuum for the removal of moisture where they remained for 12 hours. The amount of dry extract was standardized at $180 \mathrm{mg} /$ $\mathrm{ml}$ of saline.

\section{Volunteer blood donors}

Twelve healthy volunteers accepted to donate blood for the completion of the experimental protocols of this study. The volunteers did not consume any kind of medication, food supplements, or consume alcoholic drinks during the experiments. The participation of the volunteers in the study was without monetary compensation and in agreement with the human rights legislation from the Declaration of Helsinki (World Medical Association, 2013). All volunteers provided written consent and were free of medical problems in their history.

\section{Blood collection from rabbits}

An amount of 30 to $40 \mathrm{ml}$ of blood was withdrawn from the ear veins of five male New Zealand white rabbits weighing 4-6 kg each via free blood flow. The animals were housed in large cages that allowed communication among them with a constant light period of 12 hours. Access to food and water was ad libitum.

\section{Estimation of platelet aggregation}

Experiments with washed rabbit platelets were performed according to Evangelou et al. (1998), whereas for the human platelets, the procedure described by Simos et al. (2011) was followed. Briefly, blood was collected in test tubes containing citric acid and centrifuged in order to separate the plasma rich in platelets (PRP) fraction. Then, the PRP fraction was then used for the platelet experiments. Platelets concentration was fixed at $2.5 \times 10^{5}$ cells $/ \mu$ before the addition of the platelet agonists [adenosine diphosphate (ADP), platelet- activating factor (PAF), and arachidonic acid (ARA)]. The agonists' concentration was adjusted to cause maximum, irreversible accumulation in control platelets. Apart from the agonists (ADP, PAF, and ARA), a leiomyosarcoma cell line (LMS cells, isolated from histological tumors in Wistar rats) (Avdikos et al., 2007) was used for human platelet aggregation (Metsios et al., 2012). The half-maximal inhibitory concentrations (IC50) of the three extracts were then estimated. The Ca-500 aggregometer (Chronolog Co, USA) was used for the evaluation of platelet aggregation.

\section{Measurement of thromboxane A2 production by platelets}

Levels of the stable metabolite TXA2 were estimated by a radioimmune assay using the kit "TXA2/2,3-DINOR-TXA [125] RIA KIT" (Isotop company, Institute of Isotops Co. Ltd. Budapest, Hungary). Radioactivity of each sample was measured by using a $\gamma$-counter (Nucleus Co Model 1600). All samples were stored at $-80^{\circ} \mathrm{C}$ for 10 days (Benedetto et al., 1997).

\section{Flow cytometry analysis on natural killer lymphocytes}

Twenty $\mathrm{ml}$ of whole blood were collected from 12 volunteers and transferred into tubes that contained heparin as an anticoagulant. Isolation of peripheral blood mononuclear cells (PBMCs) was performed as previously described by Neri et al. (2001). NKCs were isolated from PBMC using the RosetteSep 
(Stemcell Technologies, Vancouver, Canada) method (Warren and Rana, 2003) and their functionality was evaluated against K562 chronic myeloid leukemia cells (target cells, TC). NKCs and TC were mixed in NKC/TC ratios of 12.5:1, 25:1, and 50:1. The kit used for the evaluation of NKC cytotoxicity was "NKTEST" of ORPEGEN Pharma, Germany. The estimation of cytotoxicity of NKCs was performed by flow cytometry (Toliopoulos et al., 2013). The same measurements were repeated after the incubation of cells (for 150 minutes) with $10 \mathrm{mg} / \mathrm{ml}$ of the V. album $L$. + A. Alba extract. The cytotoxic activity of the extract against TC was also evaluated without the addition of NKCs.

\section{A model of in vivo hematogenous metastatic spread in Wistar rats}

Nineteen female Wistar rats aged 3 months and weighing $175 \pm 12 \mathrm{~g}$ were used in this study. Animals were kept in laboratory cages at room temperature $\left(20^{\circ} \mathrm{C} \pm 2^{\circ} \mathrm{C}\right)$, with control lighting (12 hours light/12 hours dark). All experiments were handled in accordance with the European legislation (European Union directive for the protection of animals used for scientific purposes, 2010/63/EU) for the care and the use of laboratory animals (Institutional permission number 20EEP02).

Animals were divided into two groups: the Control Group (CG) composed of 9 rats and the Treatment Group (TG) composed of 10 rats. Inoculation of malignant cells (LMS cells) to the rats was performed according to the procedure described by Verginadis et al. (2011). The extract administered to the rats was the mixture of V. album L. $+A$. alba and the treatment lasted for 5 weeks. Animals in the TG received intraperitoneally $136 \mathrm{mg} / \mathrm{kg}$ body wt of extract in the first week, $271 \mathrm{mg} / \mathrm{kg}$ body wt of extract for the 2 week, and $406 \mathrm{mg} / \mathrm{kg}$ body wt of extract for the last 3 weeks. The gradual increase of the extract was necessary for the adaptation of animals to the chemical stress, derived from the extract's components.

After the end of the treatment period, the animals were sacrificed by the administration of Pentothal. An autopsy, a fixation of the organs in $8 \%$ formaldehyde, and a histological examination were also performed. More emphasis was given to the detection of metastasis in the lungs, liver, and in oversized and parenchymatous organs, wherein the malignant cells might afford additional metastasis.

\section{Statistical analysis}

Data are expressed as mean \pm SE. Statistical significance between data means was determined by Student's $t$-test and oneway analysis of variance (ANOVA) (SPSS version 17.0, SPSS Inc. Illinois, Chicago). $p$ values $<0.05$ were considered significant.

\section{RESULTS}

\section{Inhibition of platelet aggregation}

The three extracts exerted a dose-dependent inhibition of washed rabbit platelet aggregation. Viscum album L. extract achieved total inhibition at higher doses than the other two (Fig. 1). The sensitivity of $V$. album $L$. extract was higher to the PAF pathway compared to the ADP and ARA pathways (Fig. 1B). The $A$. alba extract, as well as the mixture of the two plants, achieved total platelet aggregation inhibition (caused by all three agonists used) in doses lower than $5 \mathrm{mg} / \mathrm{ml} \mathrm{PRP.}$

A similar effect but slightly less potent was observed to the inhibition of human platelet aggregation by the three extracts (Fig. 2). Maximum platelet aggregation was observed at higher concentrations for all three extracts. Again, $V$. album L. extract sensitivity was higher to the PAF pathway (Fig. 2B). When LMS cells were used as an agonist, a dose-dependent inhibition of human platelet aggregation was recorded for all three types of extracts regardless of the agonist used (Fig. 3). The $\mathrm{IC}_{50}$ of the three extracts for the washed rabbit and human platelets is presented in Table 1.

The platelets significantly decreased $\mathrm{TXA}_{2}$ production when the extracts were added $(10 \mathrm{mg} / \mathrm{ml}$ PRP). The three main agonists for platelet aggregation enhanced $\mathrm{TXA}_{2}$ production, with PAF being the most potent. A higher sensitivity was revealed for the ADP and ARA pathways (8-fold reduction) in comparison to the PAF pathway (4.6-fold reduction) (Fig. 4).

\section{NKCs functionality}

Incubation of the $\mathrm{K} 562$ cells with $V$ album L. + A. alba extract resulted in an increase of cancer cell deaths by $9.1 \% \pm 0.7 \%$. Incubation with $10 \mathrm{mg} / \mathrm{ml}$ of the extract resulted in a significant increase of NKCs cytotoxicity in all three ratios. The extract was able to significantly stimulate NKCs up to $340 \%$ at the
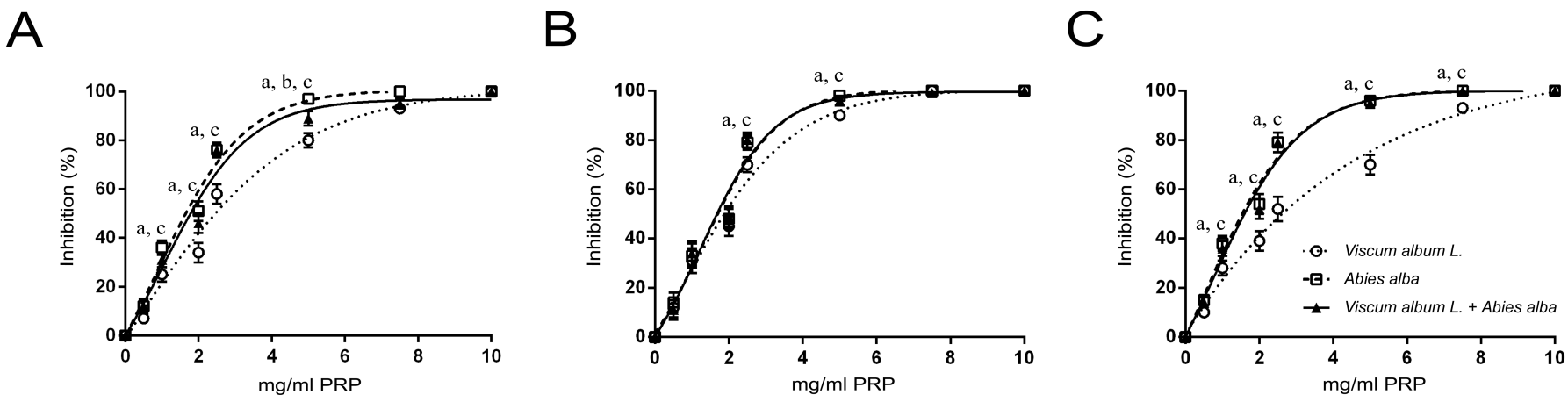

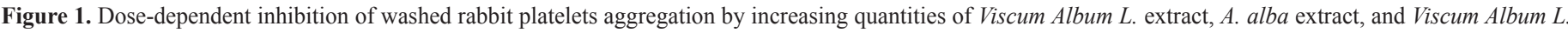

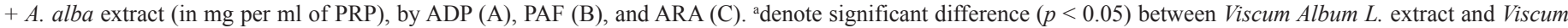

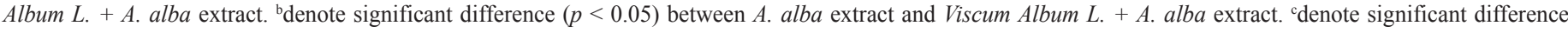
$(p<0.05)$ between Viscum Album L. extract and A. alba extract. 
A

B
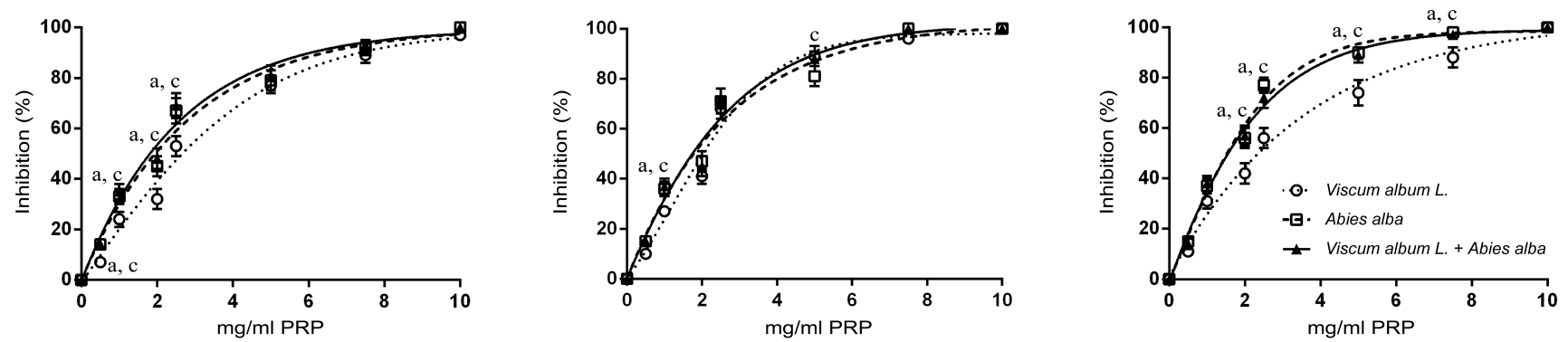

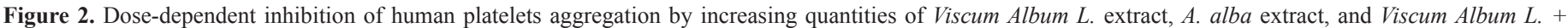

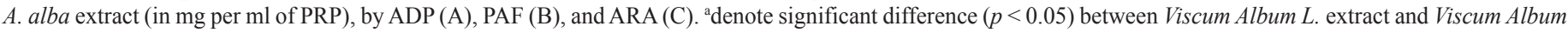

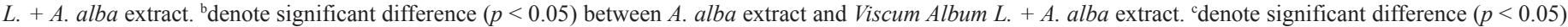
between Viscum Album L. extract and A. alba extract.

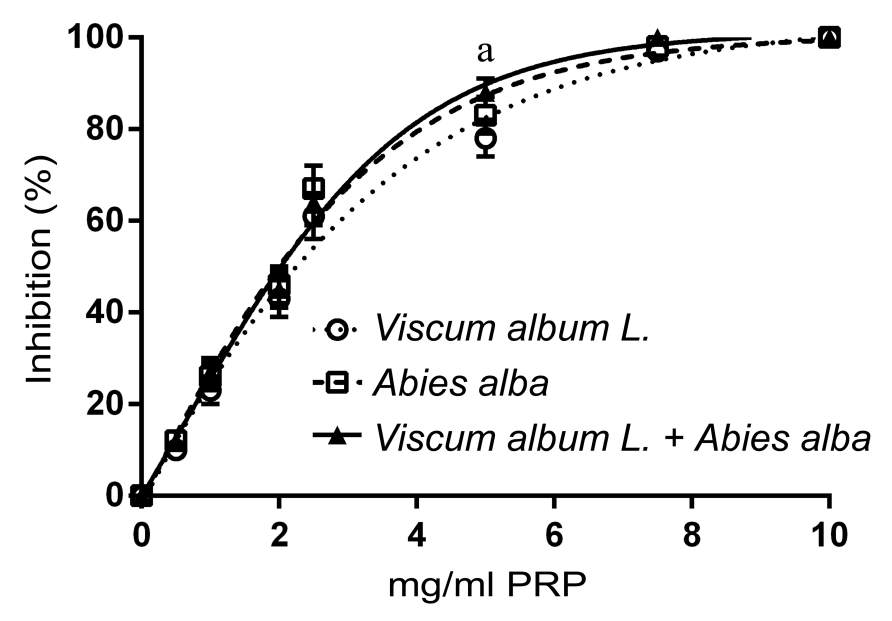

Figure 3. Dose-dependent inhibition of human platelets aggregation by increasing quantities of Viscum Album L. extract, A. alba extract, and Viscum Album L. + A. alba extract (in mg per $\mathrm{ml}$ of PRP) by LMS cells $\left(10^{6}\right.$ cells $\left./ \mathrm{ml} \mathrm{PRP}\right)$. ${ }^{a}$ denote significant difference $(p<0.05)$ between Viscum Album L. extract and Viscum Album $L .+A$. alba extract. bdenote significant difference $(p<0.05)$ between A. alba extract and Viscum Album L. + A. alba extract. ${ }^{\mathrm{c}}$ denote significant difference $(p<0.05)$ between Viscum Album L. extract and A. alba extract.

lowest ratio (12.5:1). Stimulation of the NKCs at the highest ratio (50:1) was $74 \%$ (Table 2 ).

\section{Antimetastatic activity of the $V$. album $L .+A$. alba extract}

The $V$. album $L .+A$. alba extract showed potent antimetastatic properties against tumor-bearing animals (Table 3 ). There were 60 metastatic locations observed in the CG: 36 in the liver, 17 in the lungs, and 7 in the rest of the organs. Fifteen from the 17 lung metastasis were obvious and large. On the contrary, fewer metastatic locations were observed in the TG. There were totally 14 metastatic locations: eight in the liver, one in the lungs, and five in the rest of the organs (Fig. 5). Only mild side effects were observed in a small number of TG animals which subsided after the first 2 weeks (Fig. 6).

\section{DISCUSSION}

Metastasis is the spread of cancer cells to new areas of the body (often via the lymphatic system or the bloodstream). A metastatic cancer is one that has spread from the primary site of origin (where it started) into different area(s) of the body. Depending on their tissue of origin, cancer cells subsequently spread to distinct target organs where they seed secondary tumors (Yilmaz et al., 2007). The treatment for metastatic cancer along with other factors depends on the type of cancer, the primary site of origin, the size, and the location of the metastasis and aims to slow the cancer growth or spread.

In a recent prospective randomized open-label study on overall survival, it was shown that patients with locally advanced or metastatic pancreatic cancer supplemented with a commercial form of the $V$. album $L$. extract (the drug Iscador $^{\circledR}$ Qu spezial) for 12 months had no liver metastasis (Tröger et al., 2013). There are several in vitro and in vivo studies supporting that the ability of $V$. album $L$. to inhibit metastasis results from the inhibition of angiogenesis. Specifically, Korean $V$. album $L$. extract induces TNF- $\alpha$ that results in the inhibition of endothelial cells growth and to the suppression of tumor-induced angiogenesis (Yoon et al., 1995). The antiangiogenic activity of Korean $V$. album $L$. extract was verified by chorioallantoic membrane assay in C57BL6 mice inoculated with B16-BL6 melanoma cells and treated with the extract (Park et al., 2001). In vitro angiogenesis assay (matrigel) showed that the European $V$. album $L$. extract antiangiogenic activity is correlated to its high cytotoxic effect towards endothelial cells (EA-hyp926 cells) (Elluru et al., 2009). The findings from these studies support that $V$. album $L$. extracts strongly inhibit metastasis. We observed that treatment with the $V$. album $L$. and $A$. alba extracts not only resulted in a significant reduction in the number of metastatic locations but also in the total regression of $30 \%$ of the animals' tumors.

Coagulation of platelets to cancer cells is essential for metastasis. It has been shown that surface shielding by platelet aggregates protects tumor cells from NKC lysis (Nieswandt et al., 1999) and reduces the cytotoxic activity of TNF- $\alpha$ (Neri et al., 2001). Thus, substances with antiplatelet properties might be of 
Table 1. Platelet aggregation IC50 (mg/ml PRP) of the three extracts.

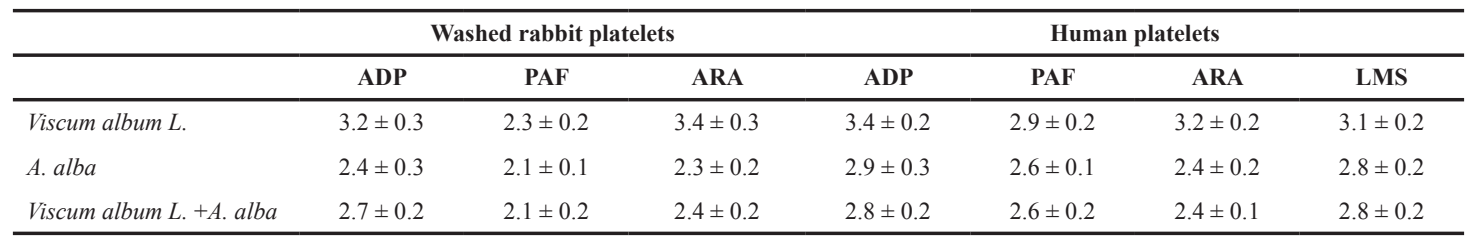

ADP, adenosine diphosphate; PAF, platelet activating factor; ARA, arachidonic acid; LMS, leiomyosarcoma cells; PRP, platelet rich plasma.

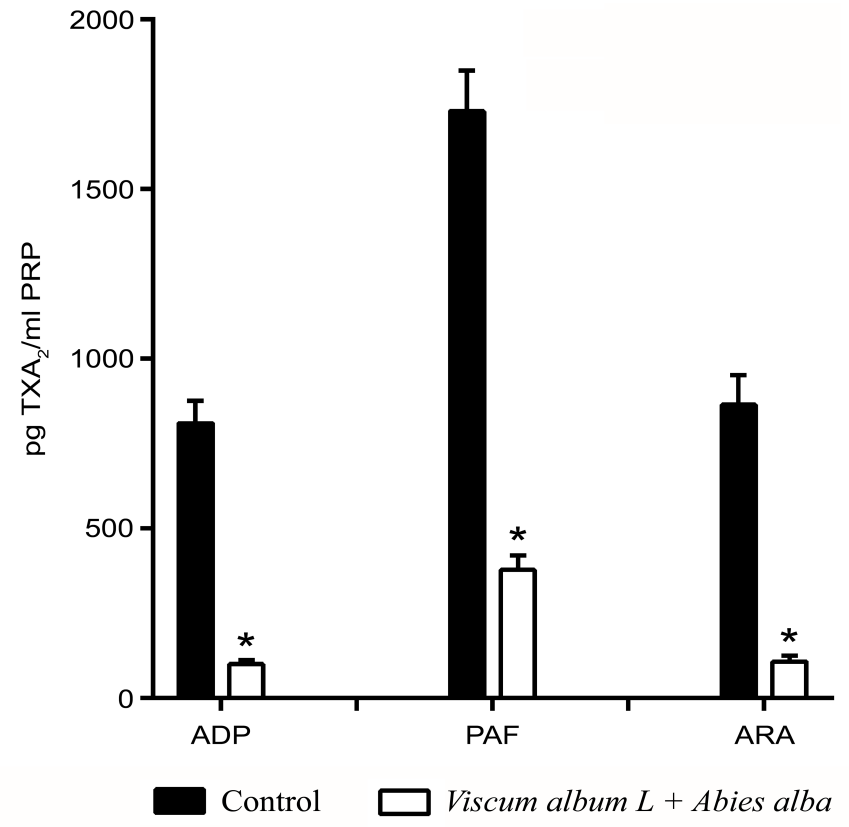

Figure 4. Inhibition of TXA 2 platelet production by the Viscum Album L. + A. alba extract. The baseline levels of $\mathrm{TXA}_{2}$ from resting platelets were used as control. ${ }^{*} p<0.05$.

Table 2. Mean percentages (\%) of cytotoxicity of NKCs against K562 TC after incubation with $10 \mathrm{mg} / \mathrm{ml}$ of the Viscum album L. + A. alba extract.

\begin{tabular}{cccc}
\hline \multicolumn{3}{c}{ NKCs:TC ratio } \\
\hline & $\mathbf{1 2 . 5 : 1}$ & $\mathbf{2 5 : 1}$ & $\mathbf{5 0 : 1}$ \\
\hline Viscum album L. + A. alba & $340 \pm 21$ & $165 \pm 25$ & $74 \pm 16$ \\
\hline
\end{tabular}

great importance in the defense of the organism against the spread of cancer cells and the formation of metastatic cancer tumors. We used washed rabbit platelets to exclude coagulation factors from the plasma in order to study cell-to-cell interaction. All three extracts inhibited platelet aggregation in a dose-dependent manner and these results were also confirmed in human platelets. These results might indicate that the extracts contain substances that act directly on the platelets rather than indirectly through the coagulation factors of plasma. Moreover, the ability of these three extracts to inhibit platelet aggregation induced by all platelet stimulators used (ADP, PAF, and ARA) suggests that they acted as non-selective anticoagulation agents.
Table 3. Tumor locations in the main organs of Wistar rats.

\begin{tabular}{lcccc}
\hline & \multicolumn{2}{c}{ Control Group } & \multicolumn{2}{c}{ Treatment Group } \\
\cline { 2 - 5 } & $\begin{array}{c}\text { No. } \\
\text { animals }\end{array}$ & $\begin{array}{c}\text { No. } \\
\text { locations }\end{array}$ & $\begin{array}{c}\text { No. } \\
\text { animals }\end{array}$ & $\begin{array}{c}\text { No. } \\
\text { locations }\end{array}$ \\
\hline Liver & 6 & 36 & 4 & 8 \\
Upper respiratory system and lungs & 5 & 17 & 1 & 1 \\
Lymph nodes & 2 & 2 & 2 & 2 \\
Pericardium & 1 & 1 & 1 & 1 \\
Gastrointestinal-urogenital system & 1 & 1 & 0 & 0 \\
Thyroid gland & 1 & 1 & 0 & 0 \\
Spleen & 1 & 1 & 0 & 0 \\
Pectoralis major & 1 & 1 & 0 & 0 \\
Upper clavicle fossa & & & 1 & 1 \\
(injection area) & 0 & 0 & 1 & 1 \\
Pancreas & 0 & 0 & 3 & - \\
No tumor & 0 & - & $\mathbf{1 4}$ \\
Total locations & & $\mathbf{6 0}$ & &
\end{tabular}

Several studies have been conducted in order to identify the active compounds of $V$. album $L$. and A. alba. Abies alba extracts have been found to contain various classes of terpenoids fractions (Yang et al., 2008). It has been reported that terpenoids could act as peroxisome proliferator-activated receptor (PPARs) agonists (Fuentes and Palomo, 2013). PPARs are present in human platelets and their activation inhibits platelet functions (Akbiyik et al., 2004). The phytochemical profile of $V$. album $L$. includes compounds such as lectins, viscotoxins, triterpenes, flavonoids, and phenolic acids (Nazaruk and Orlikowski, 2015). We have previously shown that flavonoids like quercetin, found in the $V$. album L., increase the susceptibility of tumor cells to NKCs by decreasing platelet aggregation and stimulating the NK lymphocyte activity (Theoharis et al., 2011). Ascorbic acid, also a constituent of $V$. album $L$., inhibits platelet aggregation by reducing TXB2 levels and GpIIb/IIIA receptor's expression and enhances NKCs cytotoxicity (Toliopoulos et al., 2011).

Although the mixed extract ( $V$. album L. $+A$. alba) caused a relatively small degree of direct apoptosis to cancer cells, it successfully stimulated NKCs cytotoxicity. One of the most important findings of this study was that the immunomodulating action of the mixed extract was more profound on the ratio 12.5:1 where a small number of NKCs was involved against TC. NKCs cytotoxicity is significantly reduced in cancer (Johann et al., 2010) and thus, the potential 

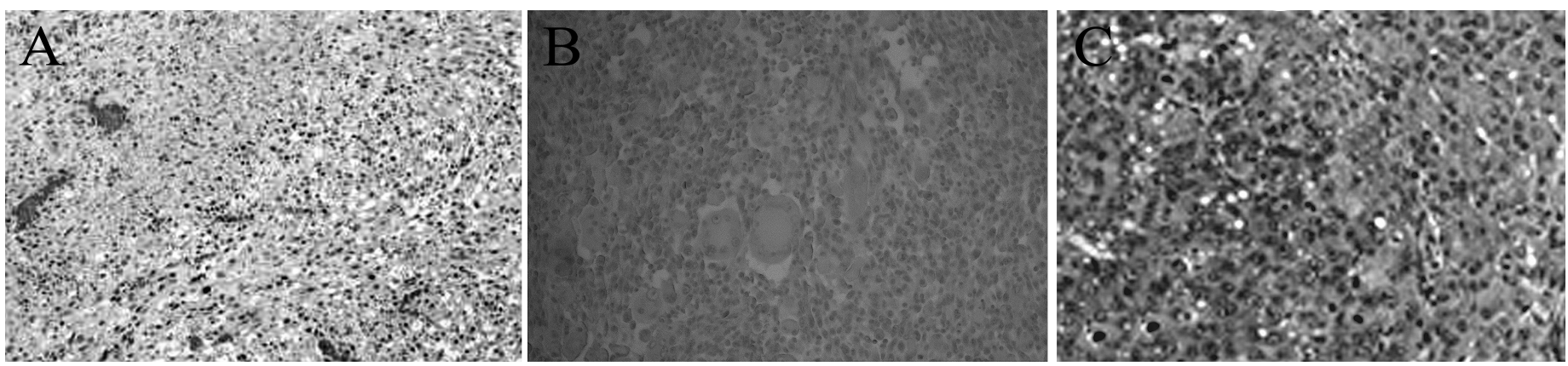

Figure 5. Primary tumor development and metastasis in tumor-bearing Wistar rats treated with the Viscum Album L. + A. alba extract. LMS (A). Lung metastasis (B). Liver metastasis (C). Tissue sections were stained with Hematoxylin-eosin. LMS and lung sections were magnified by $\times 200$ while liver section by $\times 400$.

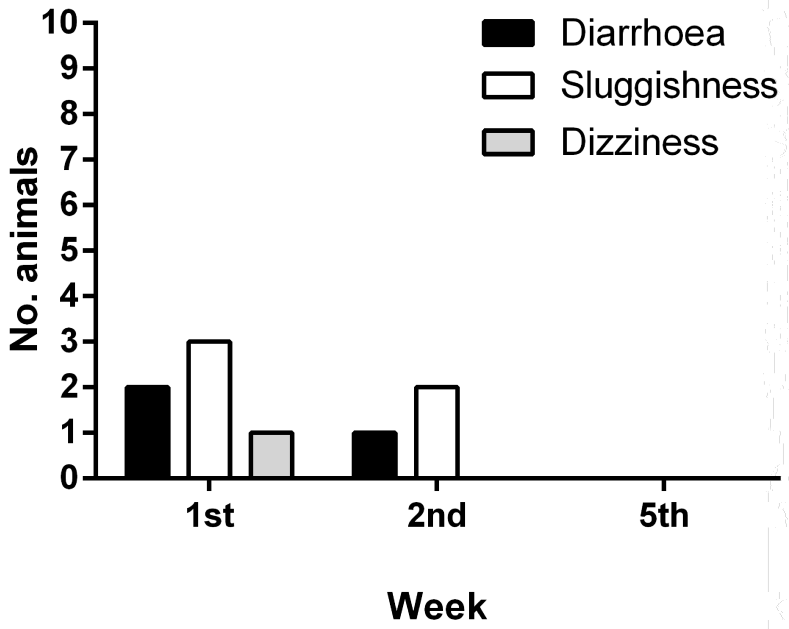

Figure 6. Tolerability of the Viscum Album L. + A. alba extract treatment.

ability of the extract to enhance their activity could be of great importance for these patients.

\section{CONCLUSION}

The $V$. album $L$. and A. alba extract exerted potent antimetastatic properties a) by inhibiting platelet aggregation and enabling NKCs to attack and destroy cancer cells and b) by enhancing NKCs cytotoxicity. Moreover, a direct anticancer activity is possible but further research is needed in order to clarify the specific compounds of these plants as well as the specific mechanism of anticancer activity.

\section{CONFLICT OF INTEREST}

The authors have declared no conflict to disclose.

\section{ACKNOWLEDGMENT}

The author gratefully acknowledges the assistance of Emeritus Professor Panagiotis Efthimiadis, Agronomist, for his assistance on the identification of the plants.

\section{REFERENCES}

Akbiyik F, Ray DM, Gettings KF, Blumberg N, Francis CW, Phipps RP. Human bone marrow megakaryocytes and platelets express PPARgamma, and PPARgamma agonists blunt platelet release of CD40 ligand and thromboxanes. Blood, 2004; 104:1361-8.
Amo L, Tamayo-Orbegozo E, Maruri N, Eguizabal C, Zenarruzabeitia O, Riñón M, Arrieta A, Santos S, Monge J, Vesga MA, Borrego F. Involvement of platelet-tumor cell interaction in immune evasion. Potential role of podocalyxin-like protein 1. Front Oncol, 2014; $4: 245$.

Avdikos A, Karkabounas S, Metsios A, Kostoula O, Havelas K, Binolis J, Verginadis I, Hatziaivazis G, Simos I, Evangelou A. Anticancer effects on leiomyosarcoma-bearing Wistar rats after electromagnetic radiation of resonantradiofrequencies. Hell J Nucl Med, 2007; 10:95-101.

Benedetto C, Mc Donalt-Gibsor RC, Nigam S, Slater TF. Prostaglandins and Related Substances. A Practical Approach. Oxford IRL Press Ltd, Oxford, UK, 1997.

Böhling N, Greuter W, Raus T, Snogerup B, Snogerup S, Snogerup BS. Notes on the Cretan mistletoe, Viscum album subsp. Creticum subsp. nova (Loranthaceae/Viscaceae). Isr J Plant Sci, 2003; 50:S77-84.

Choi SH, Lyu SY, Park WB. Mistletoe lectin induces apoptosis and telomerase inhibition in human A253 cancer cells through dephosphorylation of Akt. Arch Pharm Res, 2004; 27(1):68-76.

Delebinski CI, Twardziok M, Kleinsimon S, Hoff F, Mulsow K, Rolff J, Jager S, Eggert A, Seifert G. A Natural combination extract of Viscum album L. containing both triterpene acids and lectins is highly effective against AML in vivo. PLoS One, 2015; 10(8):e0133892.

Elluru SR, Duong Van Huyen JP, Delignat S, Prost F, Heudes D, Kazatchkine MD, Friboulet A, Kaveri SV. Antiangiogenic properties of viscum album extracts are associated with endothelial cytotoxicity. Anticancer Res, 2009; 29(8):2945-50.

Evangelou AM, Malamas MP, Vezyraki P, Karkabounas SC. Is epinephrine-induced platelet aggregation autoregulated by its metabolic degradation products in vivo? In vivo, 1998; 12:321-5.

Fuentes E, Palomo I. Relationship between Platelet PPARs, cAMP Levels, and P-Selectin Expression: Antiplatelet Activity of Natural Products. Evid Based Complement Alternat Med, 2013; 861786.

Gay LJ, Felding-Habermann B. Contribution of platelets to tumour metastasis. Nat Rev Cancer, 2011; 11:123-34.

Gupta GP, Massague J. Platelets and metastasis revisited: a novel fatty link. J Clin Invest, 2004; 114:1691-3.

Horneber MA, Bueschel G, Huber R, Linde K, Rostock M. Mistletoe therapy in oncology. Cochrane Database Syst Rev, 2008; 2:CD003297.

Johann PD, Vaegler M, Gieseke F, Mang P, Armeanu-Ebinger S, Kluba T, Handgretinger R, Müller I. Tumour stromal cells derived from paediatric malignancies display MSC-like properties and impair NK cell cytotoxicity. BMC Cancer, 2010; 10:501.

Kienle GS, Glockmann A, Schink M, Kiene H. Viscum album L. extracts in breast and gynaecological cancers: a systematic review of clinical and preclinical research. J Exp Clin Cancer Res, 2009; 28:79.

Kim MS, Lee J, Lee KM, Yang SH, Choi S, Chung SY, Kim TY, Jeong WH, Park R. Involvement of hydrogen peroxide in mistletoe lectin-II-induced apoptosis of myeloleukemic U937 cells. Life Sci, 2003; 73(10):1231-43. 
Lyu SY, Choi SH, Park WB. Korean mistletoe lectin-induced apoptosis in hepatocarcinoma cells is associated with inhibition of telomerase via mitochondrial controlled pathway independent of p53. Arch Pharm Res, 2002; 25(1):93-101.

Metsios A, Verginadis I, Simos Y, Batistatou A, Peschos D, Ragos V, Vezyraki P, Evangelou A, Karkabounas S. Cytotoxic and anticancer effects of the triorganotin compound $\left[\left(\mathrm{C}_{6} \mathrm{H}_{5}\right)_{3} \mathrm{Sn}(\mathrm{cmbzt})\right]$ : an in vitro, ex vivo and in vivo study. Eur J Pharm Sci, 2012; 47(2):490-6.

Nazaruk J, Orlikowski P. Phytochemical profile and therapeutic potential of Viscum album L. Nat Prod Res, 2016; 30(4):373-85.

Neri S, Mariani E, Meneghetti A, Cattini L, Facchini A. Calceinacetyoxymethyl cytotoxicity assay: standardization of a method allowing additional analyses on recovered effector cells and supernatants. Clin Diagn Lab Immunol, 2001; 8:1131-5.

Nieswandt B, Hafner M, Echtenacher B, Männel DN. Lysis of tumor cells by natural killer cells in mice is impeded by platelets. Cancer Res, 1999; 59:1295-300.

Park WB, Lyu SY, Kim JH, Choi SH, Chung HK, Ahn SH, Hong SY, Yoon TJ, Choi MJ. Inhibition of tumor growth and metastasis by Korean mistletoe lectin is associated with apoptosis and antiangiogenesis. Cancer Biother Radiopharm. 2001; 16(5):439-47.

Simos Y, Metsios A, Verginadis I, D'Alessandro AG, Loiudice P, Jirillo E, Charalampidis P, Kouimanis V, Boulaka A, Martemucci G, Karkabounas S. Antioxidant and anti-platelet properties of milk from goat, donkey and cow: An in vitro, ex vivo and in vivo study. Int Dairy J, 2011; 21:901-6.

Steele ML, Axtner J, Happe A, Kröz M, Matthes H. Use and safety of intratumoral application of European mistletoe (Viscum album L) preparations in Oncology. Integr Cancer Ther, 2015; 14:140-8.

Theoharis V, Toliopoulos I, Simos Y, Metsios A, Zelovitis I, Tzora A, Liasko R, Skoufos I, Karkabounas S. Inhibition of platelet aggregation and stimulation of natural killer cells functionality by administration of flavonoids. South Asian J Exp Biol, 2011; 1:94-100.

Toliopoulos I, Simos Y, Daskalou T, Verginadis I, Evangelou A, Karkabounas S. Inhibition of platelet aggregation and immunomodulation of NK lymphocytes by administration of ascorbic acid. Indian J Exp Biol, 2011; 49:904-8.

Toliopoulos IK, Simos YV, Bougiouklis D, Oikonomidis S. Stimulation of natural killer cells by homoeopathic complexes: An in vitro and in vivo pilot study in advanced cancer patients. Cell Biochem Funct, 2013; 31:713-8.

Tröger W, Galun D, Reif M, Schumann A, Stanković N, Milićević M. Viscum album [L.] extract therapy in patients with locally advanced or metastatic pancreatic cancer: a randomised clinical trial on overall survival. Eur J Cancer. 2013; 49(18):3788-97.
Twardziok M, Kleinsimon S, Rolff J, Jager S, Eggert A, Seifert G, Delebinski CI. Multiple Active Compounds from Viscum album L. Synergistically converge to promote apoptosis in Ewing Sarcoma. PLoS One, 2016; 11(9):e0159749.

Ucar EO, Arda N, Aitken A. Extract from mistletoe, Viscum album L., reduces Hsp27 and 14-3-3 protein expression and induces apoptosis in C6 rat glioma cells. Genet Mol Res, 2012; 11(3):2801-13.

Verginadis II, Karkabounas S, Simos Y, Kontargiris E, Hadjikakou SK, Batistatou A, Evangelou A. Anticancer and cytotoxic effects of a triorganotin compound with 2-mercapto-nicotinic acid in malignant cell lines and tumor bearing Wistar rats. Eur J Pharm Sci, 2011; 42:253-61.

Vidal-Russell R, Daniel LN. The first mistletoes: Origins of aerial parasitism in Santalales. Mol Phylogenetic Evol, 2008; 47:523-37.

World Medical Association. World Medical Association Declaration of Helsinki: ethical principles for medical research involving human subjects. JAMA 2013; 310(20):2191-4.

Warren HS, Rana PM. An economical adaptation of the RosetteSep procedure for NK cell enrichment from whole blood, and its use with liquid nitrogen stored peripheral blood mononuclear cells. J Immunol Methods, 2003; 280(1-2):135-8.

Yang XW, Li SM, Shen YH, Zhang WD. Phytochemical and biological studies of Abies species. Chem Biodivers, 2008; 5:56-81.

Yilmaz M, Christofori G, Lehembre F. Distinct mechanisms of tumor invasion and metastasis. Trends Mol Med, 2007; 13:535-41.

Yoon TJ, Yoo YC, Choi OB, Do MS, Kang TB, Lee SW, Azuma I, Kim JB. Inhibitory effect of Korean mistletoe (Viscum album coloratum) extract on tumour angiogenesis and metastasis of haematogenous and nonhaematogenous tumour cells in mice. Cancer Lett. 1995; 97(1):83-91.

How to cite this article:

Zelovitis I, Peschos D, Ragos V, Vlachou AM, Kontargiris E, Dhima I, Scaltsoyiannes A, Simos YV, Chatzidimitriou M, Zachariou C, Grivas P, Evangelou A, Karkabounas S. Viscum album L. \& Abies alba borisii regis effects on platelet aggregation and tumor metastasis. J Appl Pharm Sci, 2019; 9(12):122-128. 